\title{
RESEÑAS / BOOK REVIEWS
}

Persona, 24 (1), junio del 2021

Universidad de Lima

Facultad de Psicología 

Ord, T. (2020).

\section{The Precipice. Existential Risk and the Future of Humanity}

Hachette Books, 480 pp.

El Antropoceno es la etapa geológica que se caracteriza por el impacto significativo que la actividad humana tiene sobre los ecosistemas de la Tierra. El precipicio, propuesto por el filósofo de Oxford, Toby Ord, es una etapa de la historia humana en la cual el Homo sapiens ha alcanzado el poder suficiente para su autodestrucción. Esta etapa, señala, habría empezado con la primera prueba de un arma nuclear, en julio de 1945. El trabajo de Ord es una exposición profunda, comprometida y fundamentada de los principales riesgos existenciales que amenazan la supervivencia del ser humano y las posibles medidas preventivas. En el presente texto se mencionarán algunos aspectos relevantes para establecer un llamado a la acción por parte de la comunidad psicológica, como consecuencia de un análisis de la obra de Ord.

Un riesgo existencial implica tanto la extinción, así como otras formas de permanente destrucción del potencial humano, como la incapacidad de recuperarse de un colapso social. En el libro se categorizan los riesgos en naturales (e. g. impacto de asteroides) y antropogénicos (e. g. bombas nucleares), al mismo tiempo que se especula con el mayor fundamento posible sobre sendas probabilidades de ocurrencia. Las descripciones realizadas distan de ser símiles de las ficciones sensacionalistas, pues es constante el llamado a la cautela y evaluación crítica de los datos disponibles.

La primera parte del libro está compuesta por capítulos que explican cómo se llegó a la situación actual, el desarrollo del concepto de riesgo existencial, así como las dificultades que se tienen (e. g. sesgos psicológicos) para valorar en justa medida este incipiente campo de estudio que vela por el futuro de la especie. La segunda parte 
aborda los riesgos en sí, bajo las categorías antes mencionadas y una tercera que intenta anticiparse a futuros problemas a raíz de las tecnologías en actual desarrollo. La tercera y última parte del libro ahonda en la metodología y desarrollo del estudio científico de los riesgos existenciales, así como las acciones institucionales, sociales e individuales que se pueden realizar para sumarse en la urgente y noble empresa de proteger a la humanidad, como señala el autor.

Ord remarca la proeza humana a lo largo de su historia para haber alcanzado el poder tecnológico que hoy goza. Así también, señala logros en la resolución de problemas sociales. Indicadores como la reducción de la pobreza extrema, mortalidad infantil, aumento de la literacidad y esperanza de vida son ejemplos de avances importantes en los últimos doscientos años. Otro avance es la lucha por los derechos de poblaciones minoritarias y la reducción de brechas que generan desigualdad en las oportunidades. Estos ejemplos permiten al autor reconocer un progreso moral en la humanidad. Podría decirse que la sabiduría humana se ha incrementado desde su nacimiento. Sin embargo, la velocidad a la que crece el poder tecnológico y su potencial destructivo es muy distinta a la de la sabiduría individual y colectiva para evitar dañarse a sí misma.

Se acaba de proponer que la sabiduría se ha incrementado desde el nacimiento de la humanidad. Como ejercicio imaginativo, ¿cuántos años tiene el Homo sapiens si se desea equipararlo con la esperanza de vida de una persona actual? En el texto se puede encontrar una respuesta. Partiendo de los registros fósiles se puede establecer que las especies mamíferas viven aproximadamente un millón de años antes de extinguirse (el Homo erectus vivió un millón setecientos mil años, el Homo heidelbergensis, cuatrocientos mil años). Una persona actual tiene una esperanza de vida de aproximadamente ochenta años. El Homo Sapiens nació aproximadamente hace doscientos mil años. Haciendo los cálculos, la humanidad tiene actualmente dieciséis años.

Continuando con el ejercicio imaginativo y aceptando los supuestos bajo los cuales se contempla una humanidad en su adolescencia, ¿qué reflexiones puede tener la psicología al respecto? Estamos frente a una adolescencia brillante en sus logros a tan corta edad, pero con una importante dificultad para controlar los impulsos, siendo capaz de poner en riesgo el ecosistema mundial. A continuación, una breve anécdota histórica.

Durante la crisis de los misiles, en un submarino soviético, se libró una discusión acalorada en medio de circunstancias altamente hostiles y de incertidumbre. Aquel submarino soviético estuvo a instantes de atacar a Estados Unidos con una bomba nuclear como la de Hiroshima, de no ser por la sensatez de Vasily Arkhipov. Fue él quien logró controlar los impulsos del grupo encargado de detonar la bomba. "El hombre que salvó al mundo de la tercera guerra mundial". Los detalles se pueden encontrar fácilmente en internet. La anécdota busca ilustrar la vital importancia que tiene la autorregulación de 
los impulsos para la toma de decisiones, sobre todo, cuando se tiene un enorme poder. Ese poder, en continuo crecimiento, es el que hoy la humanidad lo tiene cada vez más cerca.

Entonces, ¿qué propuestas puede realizar la psicología para educar a la humanidad en materia de control de impulsos? ¿Cómo potenciar el cultivo de la sabiduría? Allí es donde la psicología cognitiva, por ejemplo, podría pronunciarse. Escenarios como el de la crisis de los misiles pueden repetirse, pero esta vez con armas distintas y con actores de perfiles variados.

Se mencionó un poder creciente y cercano. La alusión es a la tecnología que la cuarta revolución industrial está ofreciendo. Hoy se puede acceder desde cualquier computadora a las bases de datos microbiológicos y experimentar. Los tutoriales para el biohacking están a unos clics de distancia. Por otro lado, los avances en el diseño de una inteligencia artificial general (IAG) conllevan un riesgo existencial indicado por Toby Ord: el desalineamiento entre los objetivos/valores humanos y aquellos que pueda generar una IAG (value alignment problem). Esto no solo implica un desafío técnico, sino un debate para esclarecer la naturaleza y futuro de los valores humanos. Allí, la psicología de la moral tiene una silla importante en la mesa.

Es posible que, ante tanta amenaza, se piense en la necesidad de una regulación excesiva; sin embargo, como advierte Ord, esas acciones y otras que detalla podrían ser contraproducentes para el progreso humano. Lo que se intenta enfatizar en este análisis de la obra es la urgencia por el desarrollo de la sabiduría. Este es un campo ya explorado por la psicología, pero esta vez tiene una premura y una oportunidad de poder presentar avances más sobresalientes y de aplicación masiva. Las tecnologías actuales y venideras ofrecen una verdadera oportunidad para utilizarlas con creatividad en dicho propósito.

En conclusión, la reciente obra de Toby Ord nos recuerda que la etapa histórica actual se levanta sobre los hombros de generaciones que hicieron posible observar hoy en día y desde cierta altura nuestro pasado y posible futuro. De igual manera, su libro nos señala que la altura lograda ha creado un precipicio sobre el cual camina el Homo sapiens. La adolescente humanidad debe acelerar el cultivo de su sabiduría, y la psicología debe presentar propuestas innovadoras, porque la existencia misma de la especie depende de ello.

Fabrizio López de Pomar 